\title{
Decreased cardiorespiratory fitness and slow gait speed in Thai patients after open cardiac surgery: a preliminary prospective observational study
}

\author{
DOI: https://doi.org/10.5114/pq.2020.89813
}

\author{
Kornanong Yuenyongchaiwat', Sasipa Buranapuntalug', Karan Pongpanit', Chitima Kulchanarat ${ }^{2}$ \\ ${ }^{1}$ Physiotherapy Department, Faculty of Allied Health Sciences, Thammasat University, Rangsit, Thailand \\ 2 Physical Therapy Center, Thammasat University Hospital, Rangsit, Thailand
}

Abstract

Introduction. The study purpose was to investigate the pulmonary function test, respiratory muscle $(\mathrm{RM})$ strength, functional capacity, and gait speed in Thai patients submitted to open heart surgery.

Methods. A prospective observational cohort study was designed with 48 patients who underwent open heart surgery, aged 35-70 years, both males and females. The average duration of follow-up after cardiac surgery was $16.15 \pm 4.97$ days. Spirometry, RM strength, 6-minute walk test, and 5-meter walk test were performed. ANOVAs were used to compare whether these parameters significantly changed in the preoperative, prior to discharge, and follow-up periods.

Results. Overall, 26 female and 22 male patients participated in the initial and follow-up study; the average age was $55.46 \pm$ 10.35 years. There was a significant decrease in lung function (\%predicted forced vital capacity [FVC] and \%predicted forced expiratory volume in 1 second [ $\left.\mathrm{FEV}_{1}\right]$ ), RM strength (maximal inspiratory pressure [MIP] and maximal expiratory pressure [MEP]), functional capacity, and gait speed compared with preoperative values. Before discharge from hospital, the mean \%predicted FVC was dramatically decreased to $-22.87 \pm 14.93$ and \%predicted $F E V_{1}$ was $-22.10 \pm 15.59$ compared with the preoperative period $(p<0.05)$. Furthermore, mean MIP dropped to $-24.75 \pm 17.08 \mathrm{~cm} \mathrm{H}_{2} \mathrm{O}$ and MEP to $-20.96 \pm 15.79 \mathrm{~cm} \mathrm{H}_{2} \mathrm{O}$. These values did not fully recover after discharge from hospital $(p<0.001)$.

Conclusions. Decreased lung function, RM, functional capacity, and gait speed were observed during hospitalization and follow-up time.

Key words: open heart surgery, pulmonary function, respiratory muscle strength, gait speed, functional capacity

\section{Introduction}

Open heart surgery has been associated with several physical health problems in patients, e.g., decreases in cardiovascular endurance and respiratory function. In addition, an incidence of approximately $7.5 \%$ of postoperative pulmonary complications after open heart surgery has been reported and this might lead to a hospital length-of-stay of more than 10 days in $64.3 \%$ of all cases [1]. Complications and prolonged hospital admissions increase economic costs [2]. It is well known that cardiac surgery may give rise to a reduction in function of lungs and respiratory muscles. These may result in atelectasis and decreased functional residual capacity, which lead to poor gas exchange and increased ventilation/ perfusion mismatch [3].

An early systematic review of 7 studies indicated that cardiopulmonary exercise testing was associated with postoperative morbidity and mortality in non-cardiopulmonary surgery, e.g., abdominal aortic aneurysm repair, hepatic transplantation, oesophagectomy, gastric bypass, and intra-abdominal surgery [4]. Smith et al. [5] reported that low preoperative cardiorespiratory fitness was related to high incidence of postoperative events after coronary artery bypass grafting (CABG), e.g., death during the hospitalization or less than 30 days after CABG, pneumonia, sternal wound infection, reintubation, required treatment for atrial or ventricular arrhythmias. In a statement of the American Heart Association concerning the relationship of cardiorespiratory fitness and risk of cardiovascular disease, it was suggested that cardiorespiratory fitness was a preoperative predictor of cardiovascular disease and all-cause mortality [6]. In addition, this could be a cardiovascular disease risk assessment factor in patients before heart surgery and patients with CABG [6].

A reduction in pulmonary function and respiratory muscle strength of approximately $30-60 \%$ in the $1^{\text {st }}$ week after surgery has been reported [7-10]. Cardiac rehabilitation program phase 1, inpatient cardiac rehabilitation, has been suggested to prevent pulmonary complications among patients who underwent cardiac surgery. In addition, phase 2 treatment, outpatient cardiac rehabilitation, usually starts after hospital discharge. Several studies reported the effects of open heart surgery on respiratory function among inpatients. Little is known regarding the cardiorespiratory function and gait speed in Thai patients submitted to open heart surgery during hospital stay and after discharge from hospital. Therefore, the purpose of the present study was to determine the lung function, respiratory muscle strength, functional capacity, and gait speed in patients treated with open cardiac surgery before surgery, before discharge, and at the $1^{\text {st }}$ visit after hospital discharge.

\section{Subjects and methods}

The longitudinal prospective cohort study investigated 65 consecutive patients scheduled for elective cardiac operation at the Thammasat University Hospital. The participants,

Correspondence address: Kornanong Yuenyongchaiwat, Physiotherapy Department, Faculty of Allied Health Sciences, Thammasat University, 99 Moo 18, Paholyothin Road, Klong Luang, Rangsit, Pathumthani, 12120, Thailand, e-mail: ykornano@tu.ac.th

Citation: Yuenyongchaiwat K, Buranapuntalug S, Pongpanit K, Kulchanarat C. Decreased cardiorespiratory fitness and slow gait speed in Thai patients after open cardiac surgery: a preliminary prospective observational study. Physiother Quart. 2020;28(1):24-29; doi: https:// doi.org/10.5114/pq.2020.89813. 
both male and female volunteers, were aged 35-70 years. All underwent valve replacement (e.g., aortic, mitral, tricuspid or pulmonic valve replacement) or CABG. Patients with known congestive heart failure, blood pressure higher than $180 / 100 \mathrm{~mm} \mathrm{Hg}$ or uncontrollable blood pressure, or high heart rate (more than 100 beats per minute) were excluded from the study. In addition, participants who had unstable angina, uncontrolled cardiac arrhythmia, chronic cough, high temperature within 48 hours prior to the test, or other operative treatments such as thoracotomy were also excluded. Individuals with a severe heart dysfunction (defined as left ventricular ejection fraction less than $30 \%$ ) were not recruited. Further, participants with a rate of perceived exertion higher than 13 of 20 , chest pain, dyspnoea during or after the test were terminated from the study.

Maximal inspiratory pressure (MIP) and maximal expiratory pressure (MEP) were tested with an RPM01 respiratory pressure meter (Micro Medical Ltd., United Kingdom). Lung function tests measured the forced vital capacity (FVC) and forced expiratory volume in 1 second $\left(F_{E V}\right)$. The measurements of respiratory muscle strength and lung function were performed in upright position in accordance with the American Thoracic Society/European Respiratory Society [11]. A 6-minute walk test, which is a functional capacity test, was conducted. The participants were instructed to walk $30 \mathrm{~m}$ straight along a corridor in 6 minutes [12]. All were requested to walk faster for $5 \mathrm{~m} 3$ times and then the mean duration was calculated. All evaluations were performed in patients scheduled for open heart surgery: prior to surgery (within 48 hours), prior to discharge (within 48 hours), and at the $1^{\text {st }}$ follow-up visit after discharge from the hospital.

\section{Statistical analysis}

Descriptive data are presented as percentage, mean, and standard deviation. Changes in respiratory muscle strength, lung function, functional capacity, and gait speed were cal- culated by subtracting the parameter values before discharge from the baseline ones and the follow-up values from the baseline ones. All data were converted to percentages. A normality of distribution test (Kolmogorov-Smirnov goodnessof-fit test) was performed to verify the data distribution. Separate repeated measures ANOVA test and Bonferroni post-hoc tests were conducted to compare physical health conditions, i.e., respiratory muscle strength, lung function, functional capacity, and gait speed, at the different time points: before the open heart surgery, after the surgery, and at the $1^{\text {st }}$ visit after hospital discharge. The SPSS version 21.0 (IBM Corporation, United States) software was used for all analyses, and the level of statistical significance was considered as $p<0.05$.

\section{Ethical approval}

The research related to human use has complied with all the relevant national regulations and institutional policies, has followed the tenets of the Declaration of Helsinki, and has been approved by the Ethics Committee Board of Thammasat University and Thammasat University Hospital. The study has been approved for registration in the Thai Clinical Trials Registry (identification number: TCTR 20151215002).

\section{Informed consent}

Informed consent has been obtained from all individuals included in this study.

\section{Results}

A total of 65 patients eligible for the study were evaluated for cardiorespiratory health prior to cardiac surgery. Of these, 8 did not proceed to the postoperative assessments owing to surgery cancellation $(n=1)$, postoperative complications, e.g., sepsis, ischemic stroke $(n=2)$, or discharge from hospital before the tests $(n=5)$. During the $1^{\text {st }}$ visit after discharge, 48 patients were considered (Figure 1).

\section{Assessed for eligibility $(n=87)$}

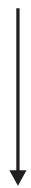

Enrolment before open heart surgery $(n=65)$

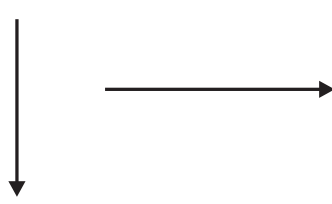

Before hospital discharge $(n=57)$

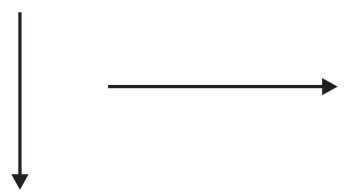

Excluded $(n=22)$ :

chest pain or dyspnoea $(n=6)$, hemodialysis and $\operatorname{ESRD}(n=5)$ LVEF $<30 \%(n=4)$, $\mathrm{CHF}(n=3)$, pericarditis $(n=1)$, postponed surgery $(n=4)$

Excluded $(n=8)$ :

surgery cancellation $(n=1)$, postoperative complications, e.g. sepsis, ischemic stroke $(n=2)$ discharge before the tests $(n=5)$

Excluded $(n=9)$ :

loss to follow-up $(n=3)$, dyspnoea during the tests $(n=1)$, never walked after discharge $(n=3)$, oedema of legs, cannot walk $(n=2)$
ESRD - end-stage renal disease LVEF - left ventricle ejection fraction $\mathrm{CHF}$ - congestive heart failure 
The characteristics of the study participants are presented in Table 1. The patients' mean age was $55.46 \pm 10.35$ years. There were 22 males and 26 females. Airflow obstruction was defined as $\mathrm{FEV}_{1} / \mathrm{FVC}$ less than 0.7 ; therefore, only 4 patients $(8.33 \%)$ were regarded as having airflow obstruction in the preoperative period. A total of 27 (56.25\%) overweight participants, with a body mass index of $\geqslant 23.0 \mathrm{~kg} / \mathrm{m}^{2}$, were noted in the study. In addition, there were no significant differences in these parameters between those who were involved in the follow-up and those who were not $(p>0.05)$. The mean length of hospital stay after the cardiac surgery was $7.77 \pm 2.85$ days and the postoperative study period equalled $16.15 \pm 4.97$ days.

One-way ANOVA and Bonferroni post-hoc tests were performed to determine whether there was a difference of cardiorespiratory function in the preoperative, postoperative, and $1^{\text {st }}$ follow-up periods (Table 2 ).

Patients who had median sternotomy showed a reduction of pulmonary volumes and respiratory muscle strength of approximately $20-34 \%$ compared with the preoperative time point $\left(-30.25 \%\right.$ for FVC, $-28.78 \%$ for $\mathrm{FEV}_{1},-33.65 \%$ for MIP, and $-26.31 \%$ for MEP). In addition, 2 weeks after surgery, i.e., on the $1^{\text {st }}$ visit after hospital discharge, the rate of recovery was not improved $(-16.85 \%$ for FVC, $-15.83 \%$ for FEV1, $-26.84 \%$ for MIP, and $-23.30 \%$ for MEP). Likewise, functional capacity and gait speed were also reduced: by $-20.01 \%$ and $-25.16 \%$, respectively, compared with the preoperative time point. Similarly, 2 weeks after the open heart surgery, the walking distance was shown to be decreased by $-4.78 \%$ and gait speed remained decreased by $-6.47 \%$. Subgroup analysis by sex found no significant differences in these values (Table 3).

In sum, significant pulmonary impairment and decreased respiratory muscle strength, functional capacity, and gait speed were observed in patients up to 2 weeks after cardiac surgery.
Table 1. Demographic data of patients undergoing open heart surgery who completed baseline and follow-up study sessions $(n=48)$

\begin{tabular}{|c|c|c|c|}
\hline Characteristics & Number (\%) & Mean & $S D$ \\
\hline \multicolumn{4}{|l|}{ Gender } \\
\hline Female & $26(54.17)$ & & \\
\hline Male & $22(45.83)$ & & \\
\hline \multicolumn{4}{|l|}{ Type of operation } \\
\hline CABG & 19 (39.58) & & \\
\hline Valve replacement/repair & $27(56.25)$ & & \\
\hline Combined & $2(4.17)$ & & \\
\hline Age (years) & & 55.46 & 10.35 \\
\hline $\mathrm{BMI}\left(\mathrm{kg} / \mathrm{m}^{2}\right)$ & & 23.80 & 3.85 \\
\hline Length of hospitalization (days) & & 7.77 & 2.85 \\
\hline Duration of follow-up (days) & & 8.38 & 3.96 \\
\hline Duration after surgery (days) & & 16.15 & 4.97 \\
\hline 6MWD (m) & & 337.55 & 122.40 \\
\hline Gait speed $(\mathrm{m} / \mathrm{s})$ & & 1.18 & 0.33 \\
\hline $\mathrm{MIP}\left(\mathrm{cm} \mathrm{H}_{2} \mathrm{O}\right)$ & & 72.69 & 24.32 \\
\hline $\operatorname{MEP}\left(\mathrm{cm} \mathrm{H}_{2} \mathrm{O}\right)$ & & 74.67 & 25.23 \\
\hline Predicted FVC (\%) & & 74.85 & 16.30 \\
\hline Predicted FEV ${ }_{1}(\%)$ & & 74.94 & 16.87 \\
\hline
\end{tabular}

$S D$ - standard deviation, CABG - coronary artery bypass grafting, $\mathrm{BMI}$ - body mass index, 6MWD - 6-minute walk distance,

MIP - maximal inspiratory pressure, MEP - maximal expiratory pressure, FVC - forced vital capacity, $\mathrm{FEV}_{1}$ - forced expiratory volume in 1 second

Table 2. Differences in cardiorespiratory function results before the open heart surgery, before discharge from hospital, and at follow-up $(n=48)$

\begin{tabular}{|l|c|c|c|}
\hline Parameter & $\begin{array}{c}\text { Mean difference } \\
\text { Before surgery \& before hospital } \\
\text { discharge }(p)\end{array}$ & $\begin{array}{c}\text { Mean difference } \\
\text { Before surgery \& at 1st follow-up }(p)\end{array}$ & $\begin{array}{c}\text { Mean difference } \\
\text { At 1st follow-up \& before hospital } \\
\text { discharge }(p)\end{array}$ \\
\hline MIP $\left(\mathrm{cm} \mathrm{H}_{2} \mathrm{O}\right)$ & $24.75 \pm 2.47(<0.001)$ & $21.04 \pm 2.64(<0.001)$ & $3.71 \pm 2.09(=0.83)$ \\
\hline MEP $\left(\mathrm{cm} \mathrm{H}_{2} \mathrm{O}\right)$ & $20.96 \pm 2.28(<0.001)$ & $19.67 \pm 2.92(<0.001)$ & $1.29 \pm 2.24(=0.567)$ \\
\hline Predicted FVC $(\%)$ & $22.88 \pm 2.15(<0.001)$ & $13.08 \pm 1.80(<0.001)$ & $9.79 \pm 2.17(<0.001)$ \\
\hline Predicted FEV $(\%)$ & $22.10 \pm 2.25(<0.001)$ & $12.19 \pm 1.97(<0.001)$ & $9.92 \pm 1.92(<0.001)$ \\
\hline 6MWD $(\mathrm{m})$ & $102.28 \pm 16.10(<0.001)$ & $43.50 \pm 16.95(=0.014)$ & $58.78 \pm 10.45(<0.001)$ \\
\hline Gait speed $(\mathrm{m} / \mathrm{s})$ & $0.36 \pm 0.04(<0.001)$ & $0.18 \pm 0.05(<0.01)$ & $0.19 \pm 0.03(<0.001)$ \\
\hline
\end{tabular}

MIP - maximal inspiratory pressure, MEP - maximal expiratory pressure, FVC - forced vital capacity, $\mathrm{FEV}_{1}$ - forced expiratory volume in 1 second, 6MWD - 6-minute walk distance

\section{Discussion}

The present study evaluated the effect of open heart surgery on cardiorespiratory function and gait speed of patients in 3 periods: before surgery, before discharge from hospital, and on the $1^{\text {st }}$ visit after discharge. In the $1^{\text {st }}$ week post-surgery, impaired lung function, reduced respiratory muscle strength, and slow gait speed were observed in the patients. In addition, the recovery rates were not improved after the $2^{\text {nd }}$ postoperative week. This suggests that cardiorespiratory function requires more than 2 weeks for full recovery.

Riedi et al. [13] investigated patients who underwent sternotomy before surgery and on the $5^{\text {th }}$ day post-surgery. They found an approximate 14\% reduction in MIP and $25 \%$ reduction in MEP on the $5^{\text {th }}$ postoperative day. Morsch et al. [14] reported that patients who underwent heart surgery showed an approximate $41 \%$ reduction in $\mathrm{FEV}_{1}$ and FVC together with 34-35\% reduction in MIP and MEP 6 days 
Table 3. Differences in cardiorespiratory function results before the open heart surgery, before discharge from hospital, and at follow-up depending on sex

\begin{tabular}{|c|c|c|c|c|c|c|}
\hline \multirow[b]{2}{*}{ Parameter } & \multicolumn{3}{|c|}{ Females $(n=26)$} & & \multicolumn{2}{|c|}{ Males $(n=22)$} \\
\hline & $\begin{array}{l}\text { Mean difference } \\
\text { Before surgery \& } \\
\text { before hospital } \\
\text { discharge } \\
\text { (p) }\end{array}$ & $\begin{array}{l}\text { Mean difference } \\
\text { Before surgery \& } \\
\text { at } 1^{\text {st }} \text { follow-up } \\
\text { (p) }\end{array}$ & $\begin{array}{l}\text { Mean difference } \\
\text { At } 1^{\text {st }} \text { follow-up \& } \\
\text { before hospital } \\
\text { discharge } \\
\text { (p) }\end{array}$ & $\begin{array}{l}\text { Mean difference } \\
\text { Before surgery \& } \\
\text { before hospital } \\
\text { discharge } \\
\text { (p) }\end{array}$ & $\begin{array}{l}\text { Mean difference } \\
\text { Before surgery \& } \\
\text { at } 1^{\text {st }} \text { follow-up } \\
\text { (p) }\end{array}$ & $\begin{array}{l}\text { Mean difference } \\
\text { At } 1^{\text {st }} \text { follow-up \& } \\
\text { before hospital } \\
\text { discharge } \\
\text { (p) }\end{array}$ \\
\hline $\mathrm{MIP}\left(\mathrm{cm} \mathrm{H}_{2} \mathrm{O}\right)$ & $\begin{array}{c}21.42 \pm 2.39 \\
\quad(<0.001)\end{array}$ & $\begin{array}{c}19.31 \pm 2.67 \\
(<0.001)\end{array}$ & $\begin{array}{l}2.12 \pm 2.64 \\
\quad(=0.43)\end{array}$ & $\begin{array}{c}28.68 \pm 4.50 \\
\quad(<0.001)\end{array}$ & $\begin{array}{c}23.09 \pm 4.85 \\
\quad(<0.001)\end{array}$ & $\begin{array}{c}5.59 \pm 3.36 \\
(=0.111)\end{array}$ \\
\hline $\operatorname{MEP}\left(\mathrm{cm} \mathrm{H} \mathrm{H}_{2} \mathrm{O}\right)$ & $\begin{array}{c}21.15 \pm 3.17 \\
\quad(<0.001)\end{array}$ & $\begin{array}{c}19.92 \pm 3.67 \\
(<0.001)\end{array}$ & $\begin{array}{c}1.23 \pm 2.72 \\
(=0.654)\end{array}$ & $\begin{array}{c}20.73 \pm 3.35 \\
\quad(<0.001)\end{array}$ & $\begin{array}{c}19.36 \pm 4.78 \\
(=0.001)\end{array}$ & $\begin{array}{c}1.36 \pm 3.76 \\
(=0.720)\end{array}$ \\
\hline Predicted FVC (\%) & $\begin{array}{c}22.23 \pm 2.87 \\
\quad(<0.001)\end{array}$ & $\begin{array}{c}10.54 \pm 2.15 \\
(<0.001)\end{array}$ & $\begin{array}{c}11.69 \pm 2.61 \\
(<0.001)\end{array}$ & $\begin{array}{c}23.64 \pm 3.33 \\
\quad(<0.001)\end{array}$ & $\begin{array}{c}16.09 \pm 2.91 \\
(<0.001)\end{array}$ & $\begin{array}{c}7.55 \pm 3.61 \\
(=0.049)\end{array}$ \\
\hline Predicted FEV (\%) & $\begin{array}{c}20.54 \pm 3.04 \\
(<0.001)\end{array}$ & $\begin{array}{c}9.69 \pm 2.49 \\
(=0.001)\end{array}$ & $\begin{array}{c}10.85 \pm 2.73 \\
(=0.001)\end{array}$ & $\begin{array}{c}23.96 \pm 3.38 \\
(<0.001)\end{array}$ & $\begin{array}{c}15.14 \pm 3.08 \\
(<0.001)\end{array}$ & $\begin{array}{c}8.82 \pm 2.72 \\
(=0.004)\end{array}$ \\
\hline 6MWD (m) & $\begin{array}{c}113.42 \pm 24.13 \\
(<0.001)\end{array}$ & $\begin{array}{c}41.50 \pm 27.11 \\
(=0.138)\end{array}$ & $\begin{array}{c}71.92 \pm 16.32 \\
(<0.001)\end{array}$ & $\begin{array}{c}89.11 \pm 20.75 \\
\quad(<0.001)\end{array}$ & $\begin{array}{c}45.86 \pm 19.20 \\
(=0.026)\end{array}$ & $\begin{array}{c}43.25 \pm 11.71 \\
(=0.001)\end{array}$ \\
\hline Gait speed (m/s) & $\begin{array}{c}0.40 \pm 0.06 \\
(<0.001)\end{array}$ & $\begin{array}{c}0.18 \pm 0.07 \\
(=0.013)\end{array}$ & $\begin{array}{c}0.22 \pm 0.05 \\
(<0.001)\end{array}$ & $\begin{array}{c}0.32 \pm 0.06 \\
(<0.001)\end{array}$ & $\begin{array}{c}0.17 \pm 0.06 \\
(=0.011)\end{array}$ & $\begin{array}{c}0.15 \pm 0.04 \\
(=0.001)\end{array}$ \\
\hline
\end{tabular}

MIP - maximal inspiratory pressure, MEP - maximal expiratory pressure, FVC - forced vital capacity, FEV $_{1}-$ forced expiratory volume in 1 second, 6MWD - 6-minute walk distance

after surgery. In contrast, Urell et al. [15] measured respiratory muscle strength and pulmonary function in 36 patients before and after cardiac surgery and revealed that only $\mathrm{FEV}_{1}$ and inspiratory capacity were decreased, which can be perceived as impaired lung function. It should be noted that the study used a time period of 2 months after heart surgery, which might have affected recovery. Several studies observed that changes in pulmonary function might persist for over 3 months after cardiac surgery $[16,17]$. Likewise, Westerdahl et al. [18] reported a $6-13 \%$ decrease in postoperative lung function, i.e., vital capacity, inspiratory capacity, $\mathrm{FEV}_{1}$, and peak expiratory flow rate, 4 months after heart operation. Therefore, pulmonary impairment remained up to 4 months after cardiac surgery.

Reduced respiratory muscle strength and pulmonary function in the early postoperative period after cardiac surgery might be due to sternal pain that affects performance in the respiratory fitness tests. Pain intensity is linked to an increased poor cardiopulmonary function. Poor pain control is manifested by an ineffective breathing pattern, resulting in poor mobility and leading to prolonged hospital stays [19]. However, the study did not report pain scales. Thus, sternal pain should be considered for cardiopulmonary recovery in patients with cardiac surgery.

Previous studies reported that increased respiratory abnormalities and impairment of lung function in patients who underwent CABG might be attributed to internal mammary artery grafting $[20,21]$. However, the present study included patients subjected to both internal mammary artery and saphenous grafting. It cannot discriminate between the results for different types of grafting.

Recovery might depend on the cardiovascular surgery type, e.g., CABG vs. valve replacement/repair, or prosthesis type for valve replacement. Previous studies reported that patients who underwent valvular surgery had lower pulmonary function values compared with CABG patients [22, 23]. El-Sobkey and Gomaa [22] claimed that patients with rheumatic heart disease commonly developed left ventricular dysfunction that led to reduced lung compliance, decreased gas exchange, and decreased pulmonary function. However, the study found no difference between types of open heart surgery, i.e., CABG or valve replacement, in terms of pulmonary function or respiratory muscle strength. Fino et al. [24] compared functional capacity, i.e., 6-minute walk test, in patients with ischemic mitral regurgitation who received bioprosthesis and mechanical prosthesis. They found that the mean 6-minute walk distance (6MWD) improved from 242 $\pm 43 \mathrm{~m}$ at baseline to $290 \pm 50 \mathrm{~m}$ at follow-up in mechanical prosthesis whereas it decreased in patients with bioprosthesis from $250 \pm 40 \mathrm{~m}$ at baseline to $220 \pm 44 \mathrm{~m}$ at follow-up. Consequently, the type of prosthetic valve might be another factor related to functional capacity. However, the study did not report any difference in prosthetic valves or intraoperative factors, e.g., cardiopulmonary bypass time or aortic crossclamping time. Therefore, the mechanisms linking postoperative pulmonary function and respiratory muscle strength with open heart surgery may not only involve types of surgery but also pain scale $[2,10,25]$ and anaesthetic techniques [26]. Several studies reported that prolonged intubation and cardiopulmonary bypass time were associated with the risk of postoperative cardiopulmonary complications including intraoperative factors $[24,27,28]$. However, these variables have not been noted in the present study and should be addressed in future research.

Similarly, decreases in walking performance, i.e., functional capacity and gait speed, were observed on the $7^{\text {th }}$ and $14^{\text {th }}$ day post-surgery. The mean 6MWD before heart surgery was $339.64 \pm 118.33 \mathrm{~m}$, which is consistent with data obtained by Stewart et al. [29], who reported a walking distance for 6 minutes of $340 \pm 117 \mathrm{~m}$ in patients submitted to CABG surgery. Furthermore, the present study revealed that the mean 6MWD was $237.35 \pm 117.92 \mathrm{~m}$ at hospital discharge. Correspondingly, Oliveira et al. [30] found that the mean $6 \mathrm{MWD}$ at hospital discharge (11.3 \pm 6 days after open cardiac surgery) was $260.20 \pm 89.20 \mathrm{~m}$ in patients with a mean age of $51 \pm 13$ years. Also, Demir et al. [31] observed that the mean 6MWD in CABG patients was $349 \mathrm{~m}$ before surgery and $284 \mathrm{~m}$ at discharge from hospital. Wojtkowska et al. [32] 
revealed that the mean 6MWD before CABG was $437.2 \pm$ $54.06 \mathrm{~m}$ and showed an improved walking distance of 43.17 $\pm 104.41 \mathrm{~m}$ at the $12^{\text {th }}$ month after surgery. In the present study, 6MWD and gait speed were improved at the $1^{\text {st }}$ visit after discharge from hospital. However, the values were still lower than before the surgery. Therefore, longer duration of follow-up may, in part, account for cardiorespiratory function recovery. Further, Stein et al. [33] observed that pulmonary function and respiratory muscle strength were reduced on the $7^{\text {th }}$ postoperative day of CABG; they concluded that pulmonary function and functional capacity after CABG could recover with a cardiac rehabilitation program within 30 days after CABG. Therefore, cardiac rehabilitation phase 2 should be encouraged in patients who underwent open heart surgery.

Several studies reported that hormones and biochemistry affected the risk of developing cardiovascular disease [34-36]. However, in subgroup analysis, cardiorespiratory values were decreased after heart surgery and were not fully recovered at the $1^{\text {st }}$ follow-up after hospital discharge in both males and females. This suggests that recovery from open heart surgery is not related to sex differences and that other factors might be associated with the rate of recovery of cardiorespiratory function. However, the relatively small number of participants, 22 males and 26 females, should be noted. A larger number of male and female subjects should be enrolled in future research.

\section{Limitations}

Several limitations might have affected the results of the present study. Firstly, there was a relatively small sample size $(n=48)$. However, owing to the repeated measures design, the current study had sufficient power to detect effects with a relatively large effects size, e.g., for 6MWD, the respective statistical power was 0.99 for the 2 -tailed alpha of 0.05 . Furthermore, pain scale, prolonged intubation, and cardiopulmonary bypass time might be associated with postoperative respiratory function and may contribute to its decreased level. Thus, postoperative pain perception and intraoperative factors should be assessed. In addition, physical activity and daily life activity were not recorded after patients were discharged from hospital. These activities might add to improved cardiorespiratory fitness and gait speed.

\section{Conclusions}

In patients with open heart surgery, significantly reductions in respiratory muscle strength, pulmonary function, functional capacity, and gait speed were observed before discharge, and these cardiorespiratory values did not fully recover after discharge from hospital. Therefore, focus should be given to patient participation in cardiac rehabilitation program phase 2 (i.e., after discharge from hospital).

\section{Acknowledgements}

The authors acknowledge the help of the Physical Therapy Center, the Traumatic Ward II, and the outpatient unit at Thammasat University Hospital and the staff for their kind support. In addition, we would like to thank all the participants and their caregivers for participating in the study. Finally, we thank Asst. Prof. Opas Satdhabudha, MD, for his invaluable help. This study was partially supported from the Foundation for Thammasat Chalerm Prakiat Hospital and by a grant from Thammasat Medical Hospital Foundation.

\section{Disclosure statement}

No author has any financial interest or received any financial benefit from this research.

\section{Conflict of interest}

The authors state no conflict of interest.

\section{References}

1. Weissman C. Pulmonary complications after cardiac surgery. Semin Cardiothorac Vasc Anesth. 2004;8(3):185211; doi: $10.1177 / 108925320400800303$.

2. Taylor GJ, Mikell FL, Moses HW, Dove JT, Katholi RE, Malik SA, et al. Determinants of hospital charges for coronary artery bypass surgery: the economic consequences of postoperative complications. Am J Cardiol. 1990; 65(5):309-313; doi: 10.1016/0002-9149(90)90293-a.

3. Siafakas NM, Mitrouska I, Bouros D, Georgopoulos D. Surgery and the respiratory muscles. Thorax. 1999;54(5): 458-465; doi: 10.1136/thx.54.5.458.

4. Smith TB, Stonell C, Purkayastha S, Paraskevas P. Cardiopulmonary exercise testing as a risk assessment method in non cardio-pulmonary surgery: a systematic review. Anaesthesia. 2009;64(8):883-893; doi: 10.1111/j.13652044.2009.05983.x.

5. Smith JL, Verrill TA, Boura JA, Sakwa MP, Shannon FL, Franklin BA. Effect of cardiorespiratory fitness on shortterm morbidity and mortality after coronary artery bypass grafting. Am J Cardiol. 2013;112(8):1104-1109; doi: 10.1016/j.amjcard.2013.05.057.

6. Ross R, Blair SN, Arena R, Church TS, Després JP, Franklin BA, et al. Importance of assessing cardiorespiratory fitness in clinical practice: a case for fitness as a clinical vital sign: s scientific statement from the American Heart Association. Circulation. 2016;134(24):e653e699; doi: 10.1161/CIR.0000000000000461.

7. Guizilini S, Gomes WJ, Faresin SM, Carvalho ACC, Jaramillo JI, Alves FA, et al. Effects of the pleural drain site on the pulmonary function after coronary artery bypass grafting. Rev Bras Cir Cardiovasc. 2004;19(1):47-54; doi: 10.1590/S0102-76382004000100010.

8. Matte P, Jacquet L, Van Dyck M, Goenen M. Effects of conventional physiotherapy, continuous positive airway pressure and non-invasive ventilator support with bilevel positive airway pressure after coronary artery bypass grafting. Acta Anaesthesiol Scand. 2000;44(1):75-81; doi: 10.1034/j.1399-6576.2000.440114.x.

9. Nicholson DJ, Kowalski SE, Hamilton GA, Meyers MP, Serrette C, Duke PC. Postoperative pulmonary function in coronary artery bypass graft surgery patients undergoing early tracheal extubation: a comparison between short-term mechanical ventilation and early extubation. J Cardiothorac Vasc Anesth. 2002;16(1):27-31; doi: 10.1053/jcan.2002.29648.

10. Urell C, Westerdahl E, Hedenström H, Janson C, Emtner M. Lung function before and two days after openheart surgery. Crit Care Res Pract. 2012;2012:291628; doi: 10.1155/2012/291628.

11. American Thoracic Society/European Respiratory Society. ATS/ERS statement on respiratory muscle testing. Am J Respir Crit Care Med. 2002;166(4):518-624; doi: 10.1164/rccm.166.4.518.

12. American Thoracic Society. ATS statement: guidelines for the six-minute walk test. Am J Respir Crit Care Med. 2002;166(1):111-117; doi: 10.1164/ajrccm.166.1.at1102.

13. Riedi C, Mora CTR, Driessen T, Coutinho MDG, Mayer DM, Moro FL, et al. Relation between respiratory muscle 
strength with respiratory complication on the heart surgery. Rev Bras Cir Cardiovasc. 2010;25(4):500-505; doi: 10.1590/s0102-76382010000400013.

14. Morsch KT, Leguisamo CP, Camargo MD, Coronel CC, Mattos W, Ortiz LD, et al. Ventilatory profile of patients undergoing CABG surgery. Rev Bras Cir Cardiovasc. 2009;24(2):180-187; doi: 10.1590/S0102-7638200900 0200014.

15. Urell C, Emtner M, Hedenström H, Westerdahl E. Respiratory muscle strength is not decreased in patients undergoing cardiac surgery. J Cardiothorac Surg. 2016; 11:41; doi: 10.1186/s13019-016-0433-z.

16. Nikas DJ, Ramadan FM, Elefteriades JA. Topical hypothermia: ineffective and deleterious as adjunct to cardioplegia for myocardial protection. Ann Thorac Surg. 1998;65(1):28-31; doi: 10.1016/s0003-4975(97)01261-7.

17. Vaidya R, Husain T, Ghosh PK. Spirometric changes after open mitral surgery. J Cardiovasc Surg. 1996;37(3):295300.

18. Westerdahl E, Lindmark B, Bryngelsson I, Tenling A. Pulmonary function 4 months after coronary artery bypass graft surgery. Respir Med. 2003;97(4):317-322; doi: 10.1053/rmed.2002.1424.

19. Wynne B, Botti M. Postoperative pulmonary dysfunction in adults after cardiac surgery with cardiopulmonary bypass: clinical significance and implications for practice. Am J Crit Care. 2004;13(5):384-393; doi: 10.4037/ajcc 2004.13.5.384.

20. Berrizbeitia LD, Tessler S, Jacobowitz IJ, Kaplan P, Budzilowicz L, Cunningham JN. Effect of sternotomy and coronary bypass surgery on postoperative pulmonary mechanics: comparison of internal mammary and saphenous vein bypass grafts. Chest. 1989;96(4):873-876; doi: 10.1378/chest.96.4.873.

21. Jenkins SC, Soutar SA, Forsyth A, Keates JR, Moxham J. Lung function after coronary artery surgery using the internal mammary artery and the saphenous vein. Thorax. 1989;44(3):209-211; doi: 10.1136/thx.44.3.209.

22. El-Sobkey SB, Gomaa M. Assessment of pulmonary function tests in cardiac patients. J Saudi Heart Assoc. 2011;23(2):81-86; doi: 10.1016/j.jsha.2011.01.003.

23. Weissman C. Pulmonary function after cardiac and thoracic surgery. Anesth Analg. 1999;88(6):1272-1279; doi: 10.1097/00000539-199906000-00014.

24. Fino $C$, lacovoni $A$, Pibarot $P$, Pepper JR, Ferrero $P$, Merlo $\mathrm{M}$, et al. Exercise hemodynamic and functional capacity after mitral valve replacement in patients with ischemic mitral regurgitation: a comparison of mechanical versus biological prostheses. Circ Heart Fail. 2018; 11(1):e004056; doi: 10.1161/CIRCHEARTFAILURE.117. 004056.

25. Sasseron AB, de Figueiredo LC, Trova K, Cardoso AL, Lima NMFV, Olmos SC, et al. Does the pain disturb the respiratory function after heart surgeries? Rev Bras Cir Cardiovasc. 2009;24(4):490-496; doi: 10.1590/s010276382009000500010.

26. Apostolakis E, Filos KS, Kolestsis E, Dougenis D. Lung dysfunction following cardiopulmonary bypass. J Card Surg.2010;25(1):47-55;doi:10.1111/j.1540-8191.2009. 00823.x.

27. Naughton C, Reilly N, Powroznyk A, Aps C, Hunt T, Hunter D, et al. Factors determining the duration of tracheal intubation in cardiac surgery: a single-centre sequential patient audit. Eur J Anaesthesiol. 2003;20(3):225233; doi: 10.1017/s0265021503000383.

28. Salis S, Mazzanti VV, Merli G, Salvi L, Tedesco CC, Veglia $F$, et al. Cardiopulmonary bypass duration is an independent predictor of morbidity and mortality after cardiac surgery. J Cardiothorac Vasc Anesth. 2008;22(6): 814-822; doi: 10.1053/j.jvca.2008.08.004.

29. Stewart RAH, Szalewska D, Stebbins A, Al-Khalidi HR, Cleland JGH, Rynkiewicz A, et al. Six-minute walk distance after coronary artery bypass grafting compared with medical therapy in ischaemic cardiomyopathy. Open Heart. 2018;5(1):e000752; doi: 10.1136/openhrt-2017000752.

30. Oliveira GU, Oliveira Carvalho V, de Assis Cacau LP, de Araújo Filho AA, de Cerqueira Neto ML, da Silva WM Jr, et al. Determinants of distance walked during the sixminute walk test in patients undergoing cardiac surgery at hospital discharge. J Cardiothorac Surg. 2014;9:95; doi: 10.1186/1749-8090-9-95.

31. Demir R, Hatemi AC, Kucukoglu S, Yigit Z, Gurses HN. Evaluation of preoperative and postoperative exercise capacity by using six-minute walk test. Eur Respir J. 2012; 40(Suppl 56):P4519.

32. Wojtkowska J, Wojtkowska I, Wolszakiewicz J. 6-minute walking test in patients after CABG - assessment of exercise capacity. Adv Rehab. 2015;29(2):19-24; doi: 10.1515/rehab-2015-0023.

33. Stein R, Maia CP, Silveira AD, Chiappa GR, Myers J, Ribeiro JP. Inspiratory muscle strength as a determinant of functional capacity early after coronary artery bypass graft surgery. Arch Phys Med Rehabil. 2009;90(10):16851691; doi: 10.1016/j.apmr.2009.05.010.

34. Pérez-López FR, Larrad-Mur L, Kallen A, Chedraui P, Taylor HS. Gender differences in cardiovascular disease: hormonal and biochemical influences. Reprod Sci. 2010; 17(6):511-531; doi: 10.1177/1933719110367829.

35. Stanhewicz AE, Wenner MM, Stachenfeld NS. Sex differences in endothelial function important to vascular health and overall cardiovascular disease risk across the lifespan. Am J Physiol Heart Circ Physiol. 2018;315(6): H1569-H1588; doi: 10.1152/ajpheart.00396.2018.

36. Palmisano BT, Zhu L, Eckel RH, Stafford JM. Sex differences in lipid and lipoprotein metabolism. Mol Metab. 2018;15:45-55; doi: 10.1016/j.molmet.2018.05.008. 